\title{
Comportamento ingestivo de ovinos alimentados com dietas compostas de silagem de capim-elefante amonizada ou não e subprodutos agroindustriais
}

\section{Gleidson Giordano Pinto de Carvalho, Aureliano José Vieira Pires ${ }^{2,4}$, Robério Rodrigues Silva $^{3}$, Cristina Mattos Veloso ${ }^{2,4}$, Herymá Giovane de Oliveira Silva ${ }^{2}$}

1 Doutorando em Zootecnia, UFV, Viçosa, MG. Rua Estrelas, 270, Sagrada Família, CEP: 36.570-000 Viçosa, MG.

2 UESB/DTRA - Itapetinga, BA.

${ }^{3}$ Doutorando em Zootecnia - UEM, Maringá, PR

${ }^{4}$ Pesquisador do CNPq.

RESUMO - Foram estudados os efeitos do uso de silagem de capim-elefante amonizada ou não com uréia ( $5 \%$ na base da MS) e da substituição do concentrado (milho e farelo de soja) por farelo de cacau (FC) ou torta de dendê (TD) na dieta sobre o comportamento ingestivo de ovinos Santa Inês. Dezoito ovinos machos não-castrados (peso médio inicial de 22,62 kg), alojados em baias individuais, foram distribuídos em delineamento experimental inteiramente casualizado, com seis tratamentos, dois volumosos (silagem de capim-elefante amonizada ou não com uréia) e três níveis de substituição do concentrado (milho + farelo de soja) por farelo de cacau ou torta de dendê ( $0 \%$ FC e TD, $40 \%$ FC e $40 \%$ TD) na dieta, fornecida na proporção de 60:40 volumoso:concentrado. O período experimental foi de 78 dias, sendo 15 dias destinados à adaptação dos animais às dietas. Os animais foram observados a cada cinco minutos, durante dois períodos de 24 horas/dia, no final do período experimental. Foram registrados o tempo despendido em alimentação, ruminação e ócio e o número e o tempo de mastigações merícicas por bolo ruminado. Não houve diferença entre os tempos de alimentação, ruminação e ócio. A amonização do capim-elefente e a inclusão do farelo de cacau no concentrado aumentaram a eficiência de ruminação, mas a maioria dos parâmetros do comportamento ingestivo avaliados não sofreu alterações.

Palavras-chave: alimentação, farelo de cacau, ruminação, torta de dendê, tratamento químico

\section{Ingestive behaviour of sheep fed with ammoniated or non-ammoniated elephantgrass silage and agro industrial by-products}

\begin{abstract}
The effects of feeding elephantgrass silage ammoniated or not with urea (5\% DM basis) and the concentrate replacement (corn and soybean meal) by cocoa meal (CM) or palm cake (PC) on the ingestive behaviour of 18 Santa Inês non-castrated male sheep averaging $22.62 \mathrm{~kg}$ of initial body weight were studied. The animals were allotted to individual pensas a completely randomized design with six treatments, two roughages (elephantgrass silage ammoniated with urea or not) and three concentrate replacement level with by cocoa meal or palm cake ( $0 \% \mathrm{CM}$ and PC, 40\% CM and 40\% PC), with 60:40 roughage:concentrate proportion. The experimental period lasted 78 days (15 days for diet adaptation). The animals were observed every five minutes, during two- 24 hour/day periods, at the end of the experimental period. In each observation period, the following variables were measured: time spent eating, time spent ruminating, time spent in idle, and number and time of ruminating chews per ruminated bolus. There was no significant difference between eating, ruminating and idle times. The elephantgrass ammoniated and the inclusion of cocoa meal in the concentrate increased the rumination efficiency, however, the majority of the evaluated ingestive behaviour parameters were not influenced by the treatments.
\end{abstract}

Key Words: chemical treatment, cocoa meal, feeding, palm cake, rumination

\section{Introdução}

As diversas condições de alimentação podem modificar os parâmetros do comportamento ingestivo. A utilização de alimentos volumosos em dietas para ruminantes é praticamente indispensável, pois, segundo Mertens (1997), estimula a atividade mastigatória e reduz a produção de ácidos. A redução do desempenho animal decorrente da menor quantidade de fibra na dieta é representada por uma série de eventos que se iniciam pela redução da atividade mastigatória, que resulta na menor secreção de saliva, favorecendo a redução do $\mathrm{pH}$ ruminal.

A necessidade de intensificação dos sistemas de produção de carne ovina no Brasil tem levado à busca por alternativas que possibilitem melhores combinações de alimentos e redução do custo de dietas. Contudo, as proprie- 
dades físicas e químicas dos subprodutos diferem das de plantas forrageiras, o que torna sua degradação e passagem pelo trato gastrintestinal diferente (Armentano \& Pereira, 1997), podendo afetar o comportamento ingestivo, que é influenciado pela estrutura física e pela composição química das dietas (Carvalho et al., 2004).

Com os recentes avanços em nutrição animal, o tratamento químico de volumosos tem sido estudado em várias pesquisas. $\mathrm{O}$ aumento da digestibilidade de materiais fibrosos, por meio do tratamento com uréia está relacionado ao acréscimo do teor de nitrogênio total das forragens e ao seu efeito, rompendo ligações ésteres entre constituintes da parede celular (fração glicídica) e ácidos fenólicos com a despolimerização parcial da lignina (Pires et al., 2004a).

Outra técnica de alimentação em expansão é a utilização de subprodutos agroindustriais, como o farelo de cacau (FC) e a torta de dendê (TD), na alimentação animal. Pires et al. (2004) incluíram níveis de 0 e $30 \%$ de FC em substituição ao milho e ao farelo de soja na alimentação de ovinos Santa Inês e não encontraram diferença significativa para o desempenho dos animais. Carvalho et al. (2004), no entanto, avaliaram o comportamento ingestivo de cabras Saanen recebendo $18 \%$ de FC ou TD na dieta total e constataram que esses subprodutos influenciaram os parâmetros de comportamento ingestivo.

De acordo com Silva et al. (2004), os fatores que afetam o comportamento ingestivo estão ligados ao alimento, ao ambiente e ao animal. Neste sentido, Van Soest (1994) relatou que animais estabulados gastam aproximadamente uma hora consumindo alimentos ricos em energia ou até mais de seis horas para fontes com baixo teor de energia. O tempo despendido em ruminação é influenciado pela natureza da dieta e, provavelmente, é proporcional ao teor de parede celular dos volumosos, de modo que, quanto maior o teor de fibra na dieta, maior o tempo despendido em ruminação.
De acordo com Welch (1982), o aumento no teor de fibra indigestível não incrementa a ruminação em mais de 8 ou 9 horas/dia, sendo a eficácia de ruminação importante no controle da utilização de alimentos fibrosos.

$\mathrm{O}$ estudo do comportamento ingestivo pode propiciar nova perspectiva para o modelo convencional de abordagem científica zootécnica, abrindo novos horizontes e trazendo inovações a situações não consideradas ou mal compreendidas, principalmente quanto às práticas de manejo (Silva et al., 2004). Além disso, poderá ser utilizado como ferramenta para avaliação de dietas, possibilitando ajustar o manejo alimentar dos animais para obtenção de melhor desempenho (Mendonça et al., 2004).

Dessa forma, este trabalho foi realizado com o objetivo de avaliar o comportamento ingestivo de ovinos Santa Inês alimentados com dietas compostas de silagem de capimelefante (Pennisetum purpureum, Schum.) amonizada ou não com uréia ( $5 \%$ na base da $\mathrm{MS}$ ) e com concentrado contendo farelo de cacau ou torta de dendê em substituição parcial ao milho e ao farelo de soja.

\section{Material e Métodos}

O experimento foi realizado no período de abril a junho de 2003 no Setor de Ovinocultura e no Laboratório de Forragicultura e Pastagem do Departamento de Tecnologia Rural e Animal da Universidade Estadual do Sudoeste da Bahia.

Foram utilizados 18 ovinos da raça Santa Inês com peso médio inicial de $22,62 \mathrm{~kg}$, alojados em baias individuais $\left(1,2 \mathrm{~m}^{2}\right)$ com piso ripado de madeira, providas de comedouros e bebedouros, dispostos frontalmente em cada baia.

As dietas foram compostas de volumoso, silagem de capim-elefante (Pennisetum purpureum, Schum) amonizada ou não com 5,0\% de uréia (com base na MS) e três concen-

Tabela 1 - Proporção dos ingredientes (\%) no concentrado, com base na matéria seca

Table 1 - Ingredient proportion (\%) in the concentrate, on dry matter basis

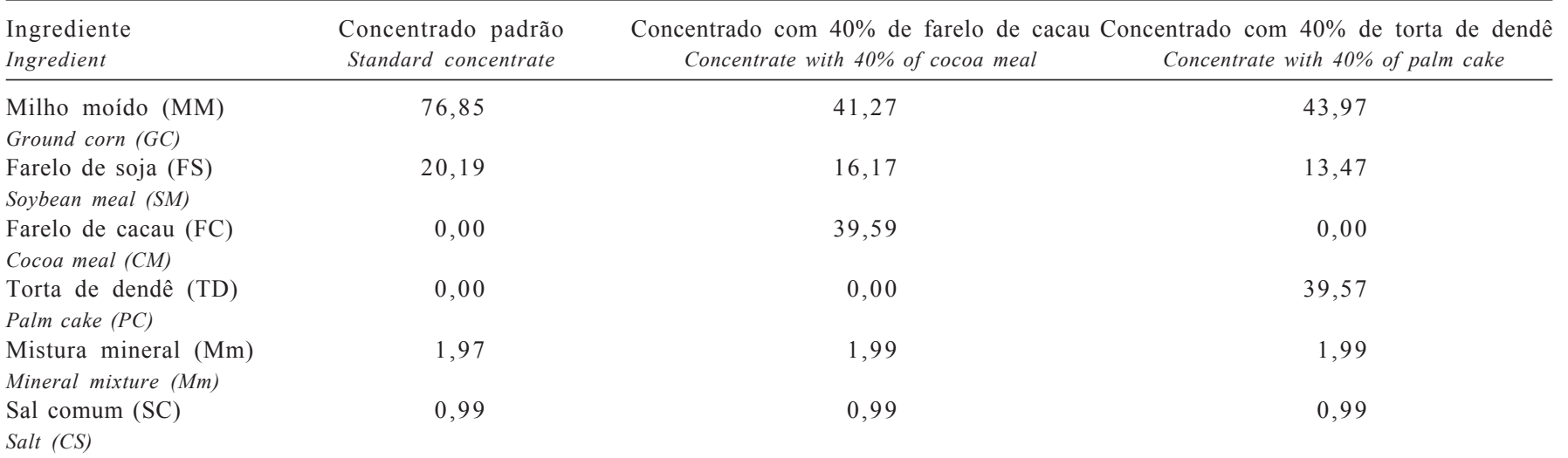


trados isoprotéicos (16\% de PB), com $0 \%$ de farelo de cacau (FC) e torta de dendê (TD), 40\% de farelo de cacau (FC) ou $40 \%$ de torta de dendê (TD) em substituição ao milho e ao farelo de soja e mistura mineral (Tabela 1). Os animais receberam água à vontade e as rações foram fornecidas duas vezes ao dia, às 8 e 15h30, na proporção de 60:40 volumoso:concentrado, em quantidade ajustada para proporcionar $10 \%$ de sobras nos cochos para o dia seguinte.

Os teores de MS, PB, FDN, FDA, hemicelulose (HEM), nitrogênio insolúvel em detergente neutro (NIDN), nitrogênio insolúvel em detergente ácido (NIDA) e cinzas dos volumosos, dos concentrados e das rações foram obtidos de acordo com as metodologias citadas por Silva \& Queiroz (2002) e os resultados são apresentados nas Tabelas 2 e 3.

O experimento teve duração total de 78 dias, os 15 primeiros para adaptação dos animais às dietas e ao ambiente, e o restante, dividido em três períodos de 21 dias, para coleta de dados.

O comportamento alimentar dos animais foi determinado nos dois últimos dias do período experimental, pela quantificação, durante 24 horas/dia (Fischer et al., 1998), do tempo despendido em alimentação, ruminação e ócio. A observação visual dos animais foi feita a cada cinco minutos por quatro observadores treinados, em sistema de revezamento, posicionados estrategicamente de forma a não incomodar os animais, e totalizou 288 observações por período. No mesmo dia, foi realizada a contagem do número de mastigações merícicas $\mathrm{MM}_{\mathrm{nb}}\left(\mathrm{n}^{\mathrm{O}} /\right.$ bolo $)$ e do tempo despendido para ruminação de cada bolo $\mathrm{MM}_{\mathrm{tb}}$ (seg/bolo), com a utilização de um cronômetro digital. Para obtenção das médias das mastigações e do tempo, foram feitas as observações de três bolos ruminais em três períodos diferentes do dia (10-12, 14-16 e 18-20 h). Foram computados o tempo e o número de mastigações por bolo ruminal por animal.

As variáveis g de MS e FDN/bolo foram obtidas dividindo-se o consumo médio individual de cada fração pelo número de bolos ruminados por dia (em 24 horas). O número diário de bolos foi obtido pela divisão do tempo total de ruminação pelo tempo médio para ruminar cada bolo, conforme descrito anteriormente. A eficiência de alimentação e ruminação, em g MS/h e g FDN/h, foi calculada por meio da divisão do consumo médio diário de MS e FDN pelo tempo total despendido em alimentação e/ou ruminação durante 24 horas, respectivamente. Estas e outras variáveis determinadas neste experimento, como o número de bolos ruminais por dia (NBR), o tempo de mastigação total (TMT) e o número de mastigações merícicas por dia $\left(\mathrm{MM}_{\mathrm{nd}}\right)$, foram obtidas conforme metodologia descrita por Bürger et al. (2000) e Polli et al. (1996).

Durante a coleta de dados, na observação noturna dos animais, o ambiente foi mantido com iluminação artificial.

O delineamento experimental utilizado foi o inteiramente casualizado, em esquema fatorial $2 \times 3$ (dois volumosos $\mathrm{x}$ três concentrados), com três repetições. As análises estatísticas dos dados foram realizadas utilizando-se o programa SAEG - Sistema de Análises Estatísticas e Genéticas (UFV, 2000) e os resultados foram interpretados estatisticamente por análise de variância e pelo teste Tukey, a $5 \%$ de probabilidade, segundo o modelo estatístico:

$$
\mathrm{Y}_{\mathrm{ijr}}=\mu+\mathrm{N}_{\mathrm{i}}+\mathrm{P}_{\mathrm{j}}+\mathrm{NP}_{\mathrm{ij}}+\mathrm{e}_{\mathrm{ijr}}
$$

em que: $\mathrm{Y}_{\mathrm{ijr}}=$ observação referente ao animal $\mathrm{r}$ na fonte de volumoso $i$ e do concentrado $j ; \mu=$ média geral; $\mathrm{N}_{\mathrm{i}}=$ efeito da fonte de volumoso $i(i=1,2) ; P_{j}=$ efeito do concentrado $\mathrm{j}(\mathrm{j}=1,2,3) ; \mathrm{NP}_{\mathrm{ij}}=$ efeito da interação volumoso $\mathrm{x}$ concentrado; e $\mathrm{e}_{\mathrm{ijr}}=$ erro aleatório associado a cada observação $(r=1,2,3)$.

Tabela 2 - Teores (\%) de PB, FDN, FDA, HEM, NIDN, NIDA e cinzas dos volumosos e concentrados Table 2 - Contents (\%) of CP, NDF, ADF, HEM, NDIN, ADIN and ash of roughages and concentrates

\begin{tabular}{|c|c|c|c|c|c|}
\hline \multirow[t]{2}{*}{$\begin{array}{l}\text { Item } \\
\text { Item }\end{array}$} & \multicolumn{2}{|c|}{$\begin{array}{l}\text { Volumoso } \\
\text { Roughage }\end{array}$} & \multicolumn{3}{|c|}{$\begin{array}{c}\text { Concentrado } \\
\text { Concentrate }\end{array}$} \\
\hline & $\begin{array}{l}\text { Não amonizado } \\
\text { Non-ammoniated }\end{array}$ & $\begin{array}{l}\text { Amonizado } \\
\text { Ammoniated }\end{array}$ & $\begin{array}{l}\text { Padrão } \\
\text { Standard }\end{array}$ & $\begin{array}{c}40 \% \text { farelo de cacau } \\
40 \% \text { of cocoa meal }\end{array}$ & $\begin{array}{c}40 \% \text { torta de dendê } \\
40 \% \text { of palm cake }\end{array}$ \\
\hline $\mathrm{PB}(C P)^{1}$ & 4,13 & 7,15 & 16,87 & 16,91 & 16,41 \\
\hline $\mathrm{FDN}(N D F)^{1}$ & 70,31 & 69,63 & 12,37 & 25,47 & 39,16 \\
\hline FDA $(A D F)^{1}$ & 34,47 & 33,07 & 4,44 & 18,27 & 21,09 \\
\hline $\mathrm{HEM}^{1}$ & 35,84 & 36,56 & 7,93 & 7,20 & 18,07 \\
\hline $\mathrm{NIDN}(N D I N)^{2}$ & 60,53 & 52,45 & 23,71 & 23,28 & 24,00 \\
\hline NIDA $(A D I N)^{2}$ & 28,75 & 20,10 & 9,26 & 9,61 & 9,90 \\
\hline Cinzas $(A s h)^{1}$ & 11,25 & 10,96 & 9,14 & 8,67 & 8,91 \\
\hline
\end{tabular}

\footnotetext{
$1 \%$ da matéria seca ( $\%$ of dry matter).
}

$2 \%$ do $\mathrm{N}$ total ( $\%$ of total $\mathrm{N}$ ). 
Tabela 3 - Teores (\%) de PB, FDN, FDA, HEM, NIDN, NIDA e cinzas das dietas

Table 3 - Contents (\%) of CP, NDF, ADF, HEM, NDIN, ADIN, and ash of the diets

\begin{tabular}{|c|c|c|c|c|c|c|}
\hline \multirow[t]{2}{*}{$\begin{array}{l}\text { Item } \\
\text { Item }\end{array}$} & \multicolumn{3}{|c|}{$\begin{array}{l}\text { Capim-elefante não-amonizado } \\
\text { Non-ammoniated elephantgrass }\end{array}$} & \multicolumn{3}{|c|}{$\begin{array}{l}\text { Capim-elefante amonizado } \\
\text { Ammoniated elephantgrass }\end{array}$} \\
\hline & $\begin{array}{l}\text { Padrão } \\
\text { Standard }\end{array}$ & $\begin{array}{l}40 \% \mathrm{FC} \\
40 \% \mathrm{CM}\end{array}$ & $\begin{array}{cc}40 \% & \text { TD } \\
40 \% & P C\end{array}$ & $\begin{array}{l}\text { Padrão } \\
\text { Standard }\end{array}$ & $\begin{array}{l}40 \% \mathrm{FC} \\
40 \% \mathrm{CM}\end{array}$ & $\begin{array}{c}40 \% \text { TD } \\
40 \% \text { PC }\end{array}$ \\
\hline $\mathrm{PB}(C P)^{1}$ & 9,22 & 9,12 & 9,04 & 11,04 & 10,93 & 10,85 \\
\hline FDN $(N D F)^{1}$ & 47,13 & 52,37 & 57,85 & 46,72 & 51,96 & 57,44 \\
\hline FDA $(A D F)^{1}$ & 22,45 & 27,98 & 29,11 & 21,62 & 27,15 & 28,28 \\
\hline NIDA $(A D I N)^{2}$ & 14,24 & 15,08 & 15,21 & 13,59 & 13,72 & 13,82 \\
\hline Cinzas $(A s h)^{1}$ & 9,99 & 9,70 & 9,84 & 9,87 & 9,59 & 9,73 \\
\hline
\end{tabular}

$1 \%$ da matéria seca ( $\%$ of dry matter).

$2 \%$ do $\mathrm{N}$ total (\% of total $\mathrm{N}$ ).

$\mathrm{FC}=$ farelo de cacau,$T D=$ torta de dendê $(C M=$ cocoa meal, $P C=$ palm cake $)$

\section{Resultados e Discussão}

A adição de uréia ao capim-elefante e a utilização de farelo de cacau e torta de dendê em substituição ao concentrado padrão (milho e farelo de soja) não provocaram alterações no comportamento alimentar (Tabela 4), ou seja, os tempos despendidos nas atividades de alimentação, ruminação e ócio foram semelhantes $(\mathrm{P}>0,05)$ em todos os tratamentos.

De acordo com Mertens (1997), o incremento da quantidade de fibra nas dietas estimula a atividade mastigatória, fato comprovado por Carvalho et al. (2006), que avaliaram o efeito de cinco níveis de FDN $(20,27,34$, 41 e $48 \%$ ) na dieta de cabras e constatou aumento nos tempos de ingestão e ruminação e diminuição do ócio com a elevação dos níveis de FDN na ração. Embora o teor de FDN das dietas testadas neste experimento tenha variado em até $10 \%$, essa tendência não foi evidenciada. Com a amonização do capim-elefante, esperava-se que os teores de FDN diminuíssem, mas isso não aconteceu, confirmando que os volumosos amonizado e não amonizado apresentaram teores de FDN semelhantes. Com base nestes resultados, pode-se inferir que o aumento do teor de fibra das dietas foi ocasionado pela adição dos subprodutos farelo de cacau ou torta de dendê. A semelhança nos tempos de alimentação, ruminação e ócio provavelmente resultou do pequeno tamanho das partículas desses alimentos (semelhante ao do concentrado). Assim, após sua ingestão pelos animais, possivelmente os microrganismos ruminais puderam colonizar e degradar com constância semelhante à observada para o milho e o farelo de soja, que compuseram integralmente o concentrado padrão (controle).

Conforme representado na Tabela 5, a ingestão de FDN em ( $\mathrm{g} / \mathrm{hora})$ foi semelhante entre os tratamentos. Mesmo com a diminuição no consumo de MS pelos animais que receberam concentrado com $40 \%$ de torta de dendê (Tabela 4), a ingestão de MS em g/hora não foi alterada.

Não foi observada diferença significativa $(P>0,05)$ (Tabela 5) entre os tratamentos para ruminação ( $\mathrm{g}$ de MS e FDN/bolo), mas verificou-se redução na eficiência de ruminação ( $\mathrm{g}$ de $\mathrm{MS} / \mathrm{h}$ ) no tratamento com $40 \%$ torta de dendê no concentrado (Tabela 6). O tipo de volumoso também afetou a eficiência, pois, nos animais que consumiram capim-elefante amonizado, a ruminação ( $\mathrm{g}$ de $\mathrm{MS} / \mathrm{h}$ ) diminuiu significativamente. Carvalho et al. (2004) descreveram que a ruminação é um recurso fisiológico acionado conforme a diminuição no tempo de alimentação para o melhor aproveitamento do alimento. Este fato não foi observado neste estudo, mas a redução no consumo de MS pelos animais que consumiram torta de dendê no concentrado possivelmente foi a causa da redução da eficiência de ruminação da MS, visto que esta variável depende do nível de ingestão do alimento.

Os resultados para a eficiência de ruminação em $\mathrm{g}$ de FDN/h também foram significativos, sendo que, para o concentrado, o menor valor foi encontrado para os animais que receberam a dieta controle, ou seja, sem a adição de subprodutos. Como o maior consumo médio diário de MS está associado, primeiramente, ao menor tempo gasto ingerindo e ruminando diariamente (Deswysen et al., 1993), constata-se que o maior consumo de MS das dietas controle e $40 \%$ de farelo de cacau provocou redução na ruminação (g de FDN/h). Embora o consumo de FDN não tenha sido significativo (Tabela 4), uma possível explicação para a redução na eficiência de ruminação é que as dietas apresentaram variações no teor de FDN com a adição de subprodutos, visto que o concentrado controle apresentou 13 e $26 \%$ menos conteúdo de FDN que aqueles com $40 \%$ de 
Tabela 4 - Consumos de MS e FDN (kg/dia), tempo despendido em alimentação, ruminação e ócio (minutos), número de bolos ruminados por dia e tempo médio em mastigações por bolo ingerido (segundos)

Table 4 - DM and NDF intakes (kg/day), time ( $\mathrm{min}$ ) spent eating, ruminating (min), and idle (min), number of ruminated bolus per day and average time (sec) spent chewing per bolus

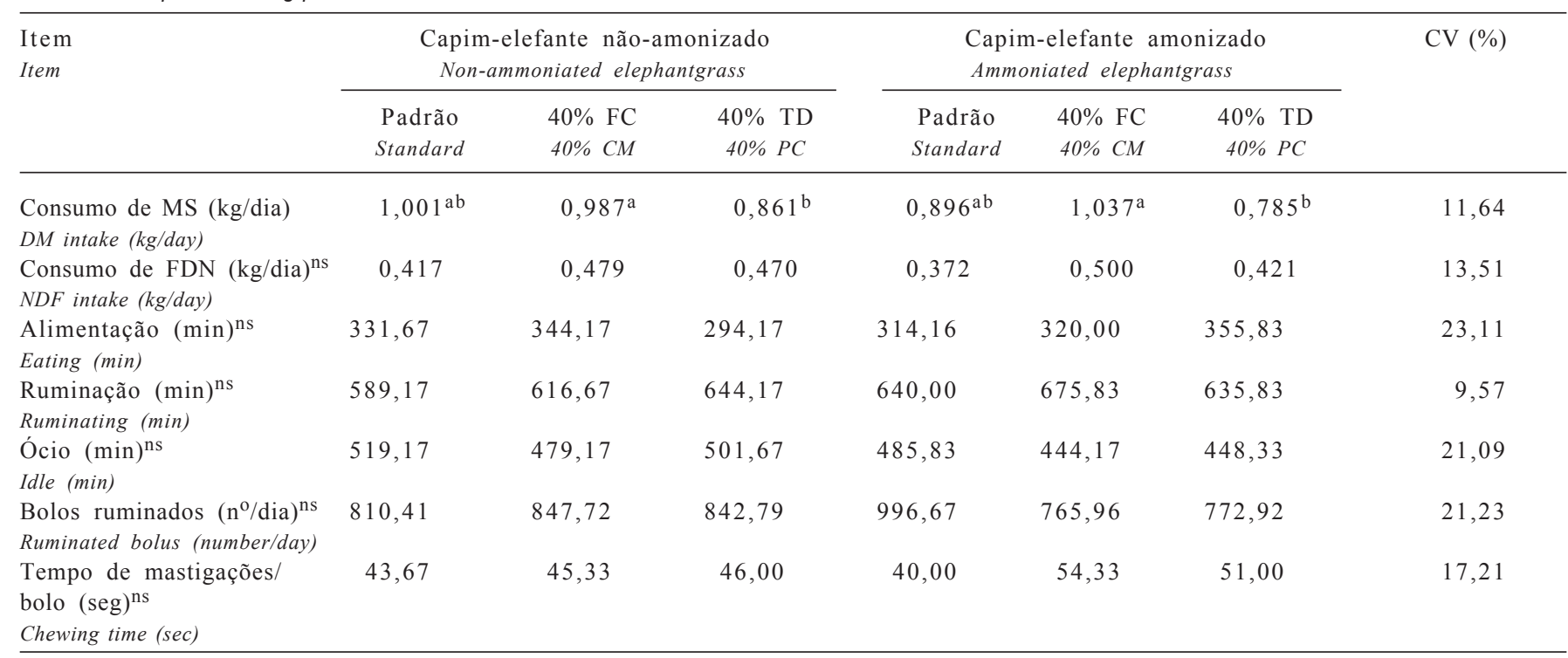

Médias seguidas de mesma letra, em uma mesma linha, não diferem pelo teste Tukey a $5 \%$ de probabilidade.

$\mathrm{CV}=$ coeficiente de variação $(\%)$.

ns = não-significativo (not significant).

Means followed by the same letter, at the same row, did not differ by Tukey test at $5 \%$ probability.

$\mathrm{CV}=$ coefficient of variation, in $\%$.

farelo de cacau e $40 \%$ de torta de dendê, respectivamente. A eficiência de ruminação da FDN também foi significativa para volumoso, sendo menor nos animais que receberam o capim-elefante amonizado. A menor quantidade de FDN ruminada, em $\mathrm{g} / \mathrm{hora}$, para este tratamento, possivelmente foi ocasionada pelo incremento da PB no capim amonizado, por ocasião da adição de uréia. De acordo com Reis et al. (2003) e Souza et al. (2001), um dos principais benefícios da amonização é que, quando os animais consomem esse alimento, as bactérias ruminais atuam com mais eficácia sobre o substrato, como conseqüência do aumento do teor de PB sintetizada a partir da adição de nitrogênio nãoprotéico (NNP).

As mastigações merícicas, expressas em horas/dia, $\mathrm{n}^{\mathrm{o}} /$ bolo e $\mathrm{n}^{\mathrm{o}}$ dia, não sofreram alterações (Tabela 5) e não foram significativas para volumoso ou para concentrado. Estes resultados corroboram os obtidos por Mendonça et al. (2004), que avaliaram o comportamento ingestivo de 12 vacas holandesas alimentadas com silagem de milho ou cana-de-açúcar sob três formas diferentes de utilização, e Bürger et al. (2000), que testaram os níveis de $30,45,60,75$ e $90 \%$ de concentrado na alimentação de cinco bezerros holandeses.

Avaliando níveis de farelo de cacau e torta de dendê no concentrado ( $18,47 \%$ na dieta total) para cabras Saanen, Carvalho et al. (2004) observaram tempo médio de mastigação total de 12,65 (h/dia) e número de mastigações de 49,84 ( $\mathrm{n}^{\mathrm{o}} /$ bolo) e $35.166,8$ ( $\left.\mathrm{n}^{\mathrm{o}} / \mathrm{dia}\right)$. Os valores obtidos neste estudo foram inferiores ao encontrados por estes autores, provavelmente em razão das diferenças na fisiologia digestiva dessas espécies, que possuem hábitos alimentares também diferentes.

Não foi observada diferença significativa para número de períodos de refeição, ruminação e ócio (n\%/dia), consumo de MS e de FDN/refeição (kg), consumo de MS e de FDN $(\mathrm{min} / \mathrm{kg})$ e tempo gasto por período refeição, ruminação e ócio (min) (Tabela 5).

O valor médio de 12,00 refeições por dia (Tabela 5) foi inferior aos de 13,10; 14,80 e 15,33 refeições, obtidos, respectivamente, por Carvalho et al. (2004), em estudo com cabras, Bürger et al. (2000), com bezerros, e Livishin et al. (1995), com vacas. Essas diferenças certamente dependem da espécie e categoria dos animais.

Os períodos de ruminação obtidos neste trabalho foram superiores aos reportados por Miranda et al. (1999). Polli et al. (1996) relataram que a distribuição da atividade de ruminação é bastante influenciada pela alimentação, pois ocorre logo após os períodos de alimentação, quando o animal está tranqüilo.

A atividade de mastigação de vacas alimentadas com com 19-20\% de FDN, compostas de silagens de milho com duas texturas nos grãos (dent ou flint) ou cana-de-açúcar, foi avaliada por Corrêa et al. (2000), que não observaram diferença na atividade de mastigação (min/dia ou min/kg de 
MS) quando as silagens de milho foram comparadas à canade-açúcar.

O tempo de mastigação tem sido uma das medidas mais estudadas e utilizadas para avaliar a efetividade da fibra decorrente de seus efeitos sobre a produção de saliva, o processo de trituração dos alimentos, o consumo de MS, o ambiente ou a função ruminal ( $\mathrm{pH}$ e perfil de AGV) e a porcentagem de gordura do leite (Colenbrander et al., 1991).

Como os tempos médios por período de refeição, ruminação e ócio são obtidos pela divisão do tempo total em 24 horas de cada atividade pelo número de períodos diários, estes parâmetros não sofreram alterações em função dos tratamentos. Esta pressuposição foi constatada no trabalho de Miranda et al. (1999), que avaliaram o comportamento ingestivo de novilhas leiteiras alimentadas com dietas à base de cana-de-açúcar. Contudo, a ruminação expressa em $\mathrm{min} / \mathrm{kg}$ de MS e FDN foi alterada com as fontes protéicas, da uréia ou da cama de frango. Os resultados encontrados neste estudo corroboram os obtidos por esses autores, pois o capim-elefante amonizado promoveu maiores

Tabela 5 - Eficiência de alimentação (g MS e FDN/h) e ruminação (g de MS e FDN/bolo), mastigações merícicas, número de períodos de refeição, ruminação e ócio ( $\mathrm{n} / \mathrm{dia})$, consumo de MS e FDN/refeição $(\mathrm{kg})$, consumo de MS e FDN (min/kg) e tempo gasto por período de refeição, em ruminação e ócio $(\min )$

Table 5 - Feeding efficiency ( $g$ DM and NDF/h), rumination ( $g$ DM and NDF/bolus), ruminating chewing, number of feeding periods, rumination periods and, idle periods (number/day), DM and NDF intake/meal (kg), DM and NDF intake (min/kg) and time spent in each meal period, ruminating or in idle ( $\mathrm{min})$

\begin{tabular}{|c|c|c|c|c|c|c|c|}
\hline \multirow[t]{3}{*}{$\begin{array}{l}\text { Item } \\
\text { Item }\end{array}$} & \multicolumn{3}{|c|}{$\begin{array}{l}\text { Capim-elefante não-amonizado } \\
\text { Non-ammoniated elephantgrass }\end{array}$} & \multicolumn{3}{|c|}{$\begin{array}{l}\text { Capim-elefante amonizado } \\
\text { Ammoniated elephantgrass }\end{array}$} & \multirow[t]{3}{*}{$\mathrm{CV} \%$} \\
\hline & Controle & $40 \% \mathrm{FC}$ & $40 \%$ TD & Controle & $40 \% \mathrm{FC}$ & $40 \%$ TD & \\
\hline & Control & $40 \% C M$ & $40 \% P C$ & Control & $40 \% C M$ & $40 \% P C$ & \\
\hline
\end{tabular}

Eficiência de alimentação (g MS e FDN/h)

Feeding efficiency ( $g \mathrm{DM}$ and $\mathrm{NDF} / \mathrm{h})$

\begin{tabular}{|c|c|c|c|c|c|c|c|}
\hline MS (DM) & 185,64 & 190,94 & 178,41 & 173,64 & 198,16 & 132,98 & 20,88 \\
\hline $\mathrm{FDN}(N D F)$ & 77,33 & 92,67 & 97,39 & 72,09 & 95,54 & 71,32 & 20,86 \\
\hline \multicolumn{8}{|c|}{$\begin{array}{c}\text { Ruminação (g de MS e FDN/bolo) } \\
\text { Ruminating ( } g \text { DM and NDF/bolus) }\end{array}$} \\
\hline MS (DM) & 1,24 & 1,23 & 1,03 & 0,93 & 1,42 & 1,06 & 22,38 \\
\hline FDN (NDF) & 0,52 & 0,60 & 0,56 & 0,38 & 0,68 & 0,57 & 22,72 \\
\hline \multicolumn{8}{|c|}{$\begin{array}{l}\text { Mastigações merícicas } \\
\text { Ruminating chewing }\end{array}$} \\
\hline Horas/dia (Hours/day) & 15,35 & 16,01 & 15,64 & 15,90 & 16,60 & 16,53 & 10,54 \\
\hline No/bolo (Number/bolus) & 67,33 & 70,67 & 65,67 & 64,33 & 87,33 & 70,67 & 16,32 \\
\hline $\mathrm{N}^{\mathrm{o}} / \mathrm{dia}^{\mathrm{ns}}$ (Number/day) & $54.255,8$ & $58.384,5$ & $55.378,0$ & $61.954,2$ & $66.237,5$ & $53.001,4$ & 15,71 \\
\hline
\end{tabular}

$\begin{array}{ll}\text { Refeição (Eating) } & 11,00 \\ \text { Ruminação (Ruminating) } & 18,83 \\ \text { Ócio (Idle) } & 26,33\end{array}$

$\operatorname{MS}(D M)$

FDN $(N D F)$

MS (DM)

FDN $(N D F)$
331,33

795,36

Número de períodos de refeição, ruminação e ócio $\left(\mathrm{n}^{\mathrm{o}} / \mathrm{dia}\right)$

Number of feeding, ruminating and idle periods (number/day)

$\begin{array}{lccccc}15,00 & 9,67 & 12,33 & 11,67 & 11,67 & 21,54 \\ 21,17 & 24,00 & 19,17 & 21,83 & 18,33 & 17,92 \\ 27,17 & 30,67 & 25,33 & 27,83 & 23,33 & 19,96\end{array}$

Consumo de MS e de FDN/refeição $(\mathrm{kg})$

$D M$ and NDF intake/meal $(\mathrm{kg})$

$\begin{array}{llllll}0,068 & 0,091 & 0,074 & 0,093 & 0,070 & 19,69 \\ 0,033 & 0,049 & 0,031 & 0,045 & 0,038 & 20,30\end{array}$

Consumo de MS e de FDN (min/kg)

$D M$ and $N D F$ intake $(\mathrm{min} / \mathrm{kg})$

$\begin{array}{ll}0,092 & 0,068 \\ 0,038 & 0,033\end{array}$

0,045

$\begin{array}{llllll}348,70 & 341,66 & 350,63 & 308,58 & 453,29 & 21,88 \\ 718,51 & 625,89 & 844,53 & 640,00 & 845,21 & 22,05\end{array}$

Tempo gasto por período de refeição, ruminação e ócio (min)

Time spent during meals, rumination and, idle (min)

\begin{tabular}{|c|c|c|c|c|c|c|c|}
\hline Refeição (Eating) & 30,74 & 22,33 & 3058 & 25,96 & 29,25 & 32,09 & 27,00 \\
\hline Ruminação(Ruminating) & 31,24 & 29,03 & 27,92 & 33,77 & 32,51 & 35,83 & 21,17 \\
\hline Ócio (Idle) & 19,91 & 17,35 & 16,43 & 19,10 & 15,82 & 20,93 & 20,65 \\
\hline
\end{tabular}

$\mathrm{CV}=$ coeficiente de variação $(\%)$

CV $=$ coefficient of variation, in \% 
Tabela 6 - Eficiências de ruminação, em g MS/h, em g FDN/h, em min/kg de MS e em min/kg de FDN, de ovinos alimentados com capimelefante amonizado ou não e concentrado contendo ou não farelo de cacau ou torta de dendê

Table 6 - Ruminating efficiency in $\mathrm{g} D M / \mathrm{h}$, ruminating efficiency in $\mathrm{g} N \mathrm{~N} F / \mathrm{h}$, ruminating in $\mathrm{min} / \mathrm{kg}$ of DM and ruminating in min/kg of NDF of sheep fed nonammoniated or ammoniated elephantgrass, with or without cocoa meal or palm kernel cake in the concentrate

\begin{tabular}{lccc}
\hline Capim-elefante & & Concentrado & Média \\
Elephantgrass & Concentrate & Mean \\
\cline { 2 - 3 } & Controle & $40 \%$ farelo de cacau & $40 \%$ de torta de dendê \\
& Control & $40 \%$ of cocoa meal & $40 \%$ of palm cake \\
\hline
\end{tabular}

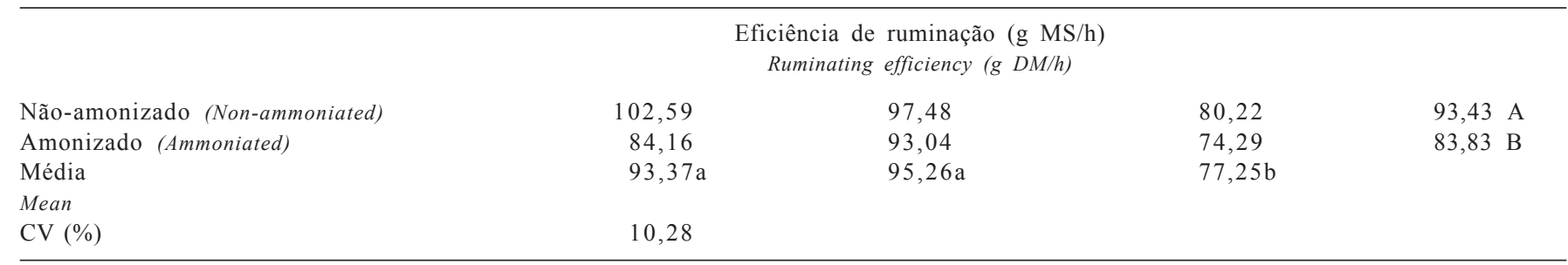

Eficiência de ruminação $(\mathrm{g} \mathrm{FDN} / \mathrm{h})$

Ruminating efficiency $(g N D F / h)$

$\begin{array}{llll}\text { Não-amonizado (Non-ammoniated) } & 42,74 & 47,31 & 43,79 \\ \text { Amonizado (Ammoniated) } & 34,94 & 44,86 & 39,84 \\ \text { Média } & 38,84 \mathrm{~b} & 46,08 \mathrm{a} & 41,82 \mathrm{ab}\end{array}$

\section{Mean}

CV (\%) 10,16

Ruminação (min/kg de MS)

Ruminating $(\mathrm{min} / \mathrm{kg}$ of $\mathrm{DM})$

Não-amonizado (Non-ammoniated)

Amonizado (Ammoniated)

Média

Mean

CV (\%)

$\begin{array}{llll}588,58 & 624,79 & 748,16 & 653,84 \mathrm{~B} \\ 714,28 & 651,72 & 809,98 & 725,33 \mathrm{~A} \\ 651,43 \mathrm{~b} & 638,25 \mathrm{~b} & 779,07 \mathrm{a} & \end{array}$

9,03

Ruminação (min/kg de FDN)

Ruminating ( $\mathrm{min} / \mathrm{kg}$ of $\mathrm{NDF}$ )

Não-amonizado (Non-ammoniated)

Amonizado (Ammoniated)

Média

Mean

CV $(\%)$
1412,87

1720,43

$1566,65 \mathrm{a}$

9,12

Médias seguidas de letras iguais minúsculas, na linha, ou maiúsculas, na coluna, não diferem entre si pelo teste Tukey a $5 \%$ de probabilidade.

Means followed by small letters, in row, or by capital letter, in column, did not differ by Tukey test at $5 \%$ probability.

tempos de ruminação (min/kg de MS e FDN) (Tabela 6). Esses incrementos na ruminação $(\mathrm{min} / \mathrm{kg})$ podem ser justificados pela menor ingestão de volumosos amonizados, visto que os animais se saciam mais rápido com a presença do NNP. Assim, durante o dia, foi despendido mais tempo para a atividade de ruminação.

\section{Conclusões}

Em um programa contínuo de alimentação de ovinos, caso haja disponibilidade, recomenda-se como alternativa alimentar o uso do farelo de cacau em substituição ao milho e farelo de soja em até $40 \%$ do concentrado ( $16 \%$ na dieta total).

A amonização do capim-elefante (Pennisetum purpureum, Schum.) com $5 \%$ de uréia têm pouca influência sobre o comportamento ingestivo de ovinos.

\section{Literatura Citada}

ARMENTANO, L.; PEREIRA, M. Simposium: meeting the fiber requirements of dairy cows. Measuring the effectives of fiber by animal trial. Journal of Dairy Science, v.80, n.7, p.14161425, 1997.

BÜRGER, P.J.; PEREIRA, J.C.; QUEIROZ, A.C. et al. Comportamento ingestivo em bezerros holandeses alimentados com dietas contendo diferentes níveis de concentrado. Revista Brasileira de Zootecnia, v.29, n.1, p.236-242, 2000.

CARVAlHO, G.G.P.; PIRES, A.J.V.; SIlVA, F.F. et al. Comportamento ingestivo de cabras leiteiras alimentadas com farelo de cacau ou torta de dendê. Pesquisa Agropecuária Brasileira, v.39, n.9, p.919-925, 2004.

CARVALHO, S.; RODRIGUES, M.T.; BRANCO, R.H. et al. Comportamento ingestivo de cabras Alpinas em lactação alimentadas com dietas contendo diferentes níveis de fibra em detergente neutro proveniente da forragem. Revista Brasileira de Zootecnia, v.35, n.2, p.562-568, 2006.

COLENBRANDER, V.F.; NOLLER, C.H.; GRANT, R.J. Effect of fiber content and particle size of alfalfa silage on performance 
and chewing behavior. Journal of Dairy Science, v.74, n.12, p.2681-2681, 1991.

CORREA, C.E.S.; PEREIRA, M.N.; RAMOS, M.H. et al. Performance of dairy cows fed corn silage differing in kernel texture or sugarcane as the dietary forage. Journal of Dairy Science, v.83, n.2, p.563-569, 2000.

DESWYSEN, A.G.; DUTILleUl, P.; GODFRIN, J.P. et al. Nycterohemeral eating and ruminating pattern in heifers fed grass or corn silagem: analysis by finite fourier transform. Journal of Animal Science, v.71, n.10, p.2739-2747, 1993.

FISCHER, V.; DESWYSEN, A.G.; AMOUCHE, E.H. et al. Efeitos da pressão de pastejo sobre o padrão nectemeral do comportamento ingestivo de ovinos em pastagem. Revista Brasileira de Zootecnia, v.27, n.1, p.164-170, 1998.

LIVSHIN, N.; MALTZ, E.; EDAN, Y. Regularity of dairy cow feeding behavior with computer-controlled feeders. Journal of Dairy Science, v.78, n.2, p.296-304, 1995.

MENDONÇA, S.S.; CAMPOS, J.M.S.; VALADARES FILHO, S.C. et al. Comportamento ingestivo de vacas leiteiras alimentadas com dietas à base de cana-de-açúcar ou silagem de milho. Revista Brasileira de Zootecnia, v.33, n.3, p.723-728, 2004.

MERTENS, D.R. Creating a system for meeting the fiber requirements of dairy cows. Journal of Dairy Science, v.80, n.7, p.1463-1481, 1997.

MIRANDA, L.F.; QUEIROZ, A.C.; VALADARES FILHO, S.C. et al. Comportamento ingestivo de novilhas leiteiras alimentadas com dietas à base de cana-de-açúcar. Revista Brasileira de Zootecnia, v.28, n.3, p.614-620, 1999.

PIRES, A.J.V.; CARVALHO JR., J.N.; SILVA, F.F. et al. Farelo de cacau (Theobroma cacao) na alimentação de ovinos. Revista Ceres, v.26, n.286, p.33-46, 2004b.

PIRES, A.J.V.; GARCIA, R.; VALADARES FILHO, S.C. et al. Novilhas alimentadas com bagaço de cana-de-açúcar tratado com amônia anidra e, ou, sulfeto de sódio. Revista Brasileira de Zootecnia, v.33, n.4, p.1078-1085, 2004a.
POLLI, V.A.; RESTLE, J.; SENNA, D.B. et al. Aspectos relativos à ruminação de bovinos e bubalinos em regime de confinamento. Revista Brasileira de Zootecnia, v.25, n.5, p.987-993, 1996 .

REIS, R.A.; BERCHIELLI, T.T.; ANDRADE, P. et al. Valor nutritivo do feno de capim coast-cross (Cynodon dactylon L. Pers) submetido à amonização. ARS Veterinária, v.19, n.2, p.143149,2003

UNIVERSIDADE FEDERAL DE VIÇOSA - UFV. SAEG - Sistema de análises estatísticas e genéticas. Viçosa, MG: UFV/CPD, 2000. (Apostila).

SILVA, D.J.; QUEIROZ, A.C. Análise de alimentos: métodos químicos e biológicos. Viçosa, MG: Universidade Federal de Viçosa, 2002. 235p.

SILVA, R.R.; MAGALHÃES, A.F.; CARVALHO, G.G.P. et al. Comportamento ingestivo de novilhas mestiças de holandês suplementadas em pastejo de brachiaria decumbes. Aspectos metodológicos. Revista Electrónica de Veterinaria, v.5, n.10, p.1-7, 2004

SOUZA, A.L.; GARCIA, R.; PEREIRA, O.G. et al. Composição químico-bromatológica da casca de café tratada com amônia anidra e sulfeto de sódio. Revista Brasileira de Zootecnia, v.30, n.3, p.983-991, 2001 (supl. 1).

Van SOEST, P.J. Nutritional ecology of the ruminant. 2.ed. Ithaca: Cornell University Press, 1994. 476p.

WELCH, J.G. Rumination, particle size and passage from the rumen. Journal of Animal Science, v.54, n.4, p.885-895, 1982. 